number of pages has increased by 160 since the last edition was published five years ago. The six editors, 56 assistant editors and more than 160 contributors are to be congratulated on keeping this reference book up to date.

J. H. Gaddum

Sofiano (T.A.) English-Russian Geological Dictionary Edited by I. D. Borneman et al. State Publ. Office Techn. Theor. Literature, Moscow, 1957. Pp. 525. Price 17r. 90k.

Sofiano (T.A.) Russian-English Geological Dictionary Edited by A. P. Lebedev and V. E. Khain. Central Editorial Board, Foreign Language Scient. Techn. Dictionaries, Fizmatgiz, Moscow, 1960. Pp. 559. Price $18 \mathrm{r} .60 \mathrm{k}$. (old roubles), 1r. 86k. (new roubles).

THESE two dictionaries, well printed and bound, and of a convenient size $(21 \times 14 \times 3 \mathrm{~cm}$.), contain some 35,000 terms each. The majority of these terms consist of one word, but quite a number of them are adjectival terms, such as, for example, 'deltaic fan', or even more complex phrases like 'planar flow structure'. Besides purely geological, petrological and mineralogical terms there is a number of mining, civil engineering and allied physical, chemical and biological terms. Some adjectival terms are placed under their main term. Thus the term 'sand' is followed by 'arkose sand', 'coral sand', etc. On the whole the compiler of these two dictionaries, Madame T. A. Sofiano, has been rather generous in her collection of terms, which is all to the good. As with other dictionaries, there are occasional mistranslations. The English-Russian dictionary has also a list of English abbreviations, which is not very satisfactory, but there is no list of Russian abbreviations. In spite of these minor defects these two dictionaries represent extremely valuable auxiliary reference books for geologists. S. I. Tomk EIEFF

\section{Linear Programming}

Methods and Applications. By Saul I. Gass. Pp. xii +223. (London: MeGraw-Hill Publishing Company, Ltd., 1958.) $50 s .6 d$.

\section{Methods of Feasible Directions}

A Study in Linear and Non-Linear Programming. By Dr. G. Zoutendijk. Pp. vi +126. (Amsterdam: Elsevier Publishing Company; London: D. Van Nostrand Company, Ltd., 1960.) 30s.

THE first book is a formal mathematical text on linear programming and is to be distinguished from the many general accounts on the subject that have appeared. It contains much information that could in the past be obtained only from original papers. Although writing for those with mathematical leanings, the author has a constant eye on the practical applications of the methods he describes. The book is divided into three parts. The first contains a general introduction and some necessary mathematical background, the second describes the theoretical and computational methods available for use, and the third discusses applications. The book has already become well known in the short period that has elapsed since its publication and is to be highly recommended.

The second book has the sub-title A Study in Linear and Non-Linear Programming, and is in the nature of a research monograph. Its appreciation requires a knowledge of present-day linear programming principles and techniques such as might be obtained from the foregoing book. The first half is concerned with linear programming, and in particular with a series of improvements to the product-form algorithm. In favourable circumstances these enable substantial economies to be made in the amount of computation required.

The second half of the book is concerned with methods of solving the general convex programming problem. In all these methods one starts with a feasible solution, determines a feasible direction of advance which will increase the value of the solution, and takes a step of appropriate length in that direction. There are various methods of determining the feasible direction of advance and the length of the step to be taken. Some of these described reduce in the case of linear or quadratic problems to methods which are already well known.

M. V. WILKES

\section{Digital Computers and Nuclear Reactor Calcula- tions}

By Ward C. Sangren. Pp. xi+208. (New York and London: John Wiley and Sons, Inc., 1960.) 8.50 dollars ; $68 s$.

DROSPECTIVE readers might not gather from the title of this book that the first half contains a valuable general introduction to digital computers written by a very experienced user. This is a pity, since others than nuclear physicists and engineers might profit from this part of the book. The chapter on programming in particular has an authentic ring about it. The chapter on numerical analysis is perhaps less successful being rather too compressed for the novice and neither sufficiently comprehensive nor sufficiently critical to appeal to the expert.

The last four chapters are concerned with the solution of technical problems arising in reactor design and in other branches of nuclear engineering; their scope is indicated by their titles: "A Code for Fission-Product Poisoning", "Diffusion and AgeDiffusion Calculations", "Transport Equation-Monte Carlo", "Additional Reactor Calculations". There is a useful selected bibliography. The author remarks that the problems he describes are good examples of problems in mathematical physics that can be 'solved' sensibly with digital computers : he considers, therefore, that they should interest not only reactor specialists but also applied mathematicians, physicists, and persons professionally interested in computer applications.

M. V. WHKES

\section{Birds of Eastern and North Eastern Africa}

By C. W. Mackworth-Praed and C. H. B. Grant. Second edition. (African Handbook of Birds, Series 1, Volume 2.) Pp. viii + 1113 + plates 54-96 + photographs 7-19. (London: Longmans Green and Co., Ltd., 1960.) 50s. net.

HIS is the indispensable work of reference for all who are interested in the birds of East Africa, and it is not surprising that the demand for copies has called for a second edition. The two volumes were originally published in 1952 and 1955 ; a second edition of Volume 1 has already appeared and the revision is thus now complete. The work having been reproduced by photo-lithography, the changes are necessarily limited to additional matter inserted in spaces which had been left for the purpose and on some extra pages at the end. A supplementary index to the addenda and corrigenda is conveniently provided.
LANDSBorough Thomson 